\title{
Seção Especial: Usabilidade em Sistemas Interativos e Organizacionais
}

\section{Apresentação}

Prezados leitores.

Hoje as organizações precisam estar atentas às necessidades dos clientes frente a um mercado altamente competitivo. Neste contexto estudos sobre usabilidade são fundamentais para as organizações atenderem melhor aos clientes e compreenderem o mercado globalizado. Assim, nesta seção especial da revista Tecno Lógica estão publicados artigos decorrentes da realização do evento internacional denominado "Usabilidade em Sistemas Interativos e Organizacionais”. O Programa de Pós-Graduação em Sistemas e Processos Industriais (PPGSPI - Mestrado), da Universidade de Santa Cruz do Sul (UNISC), juntamente com o Grupo SINFOCI, da Universidad del Quindío (UNIQUINDÍO) organizou este evento pelo Projeto de Internacionalização aprovado pela FAPERGS (Fundação de Amparao à Pesquisa do Estado do Rio Grande do Sul). O evento ocorreu de 24 a 26 de setembro de 2014, na Universidade de Santa Cruz do Sul, na cidade de Santa Cruz do Sul, RS, Brasil e trouxe importantes contribuições para o desenvolvimento de estudos na área de usabilidade. Boa leitura! 